\title{
Testing the Impact of Sustainable Development Policies in Canton Geneva
}

\author{
Giuseppe Catenazzo*, Alexandre Epalle ${ }^{+}$, Emmanuel Fragnière ${ }^{*}$, Jean Tuberosa \\ ${ }^{*}$ Haute École de Gestion de Genève - Geneva School of Business \\ Administration, ${ }^{+}$Cantonal Office of Sustainable Development, Geneva, \\ Switzerland
}

\begin{abstract}
Purpose - The aim of this paper is to identify the impact of two Canton Geneva pedagogical tools devised to sensibilize the local population to sustainable development issues.

Design/methodology/approach - We have conducted a survey that attempts to verify individuals' awareness and opinion towards sustainable development as well as the influence of both tools on their routines. 992 people who live and work in Canton Geneva have answered to a questionnaire that has been administered between January and February 2008.

Findings - People feel concerned by sustainable development issues and seem to be motivated to adapt their routines to comply with its needs. However, they feel not to be sufficiently informed: experiencing either or both pedagogical tools seems to positively influence individuals’ behaviours.

Originality/value - This paper provides some measures about the impact of educational driven programmes on individuals' awareness and behaviours towards sustainable development.

Keywords - Sustainable Development, Public Policies, Survey Research, Sustainable Development Day, Sustainable Development Brochure, Public Promotion Policies

Paper type - Research paper
\end{abstract}

\section{Introduction}

"Sustainable development" (SD) is a progress that "meet(s) the needs of the present without compromising the ability of future generations to meet their own needs". This is the major definition of SD as proposed by the 1987 United Nations' "Our Common future Report of the World Commission on Environment and Development" or "Brundtland Commission's Report”.

Although several authors (see for example, Byrch et al., 2007; Catenazzo et al., 2008; Chaharbaghi and Willis, 1999; Dearing, 1999; Garvare and Isaksson, 2001; Rondinelly and Berry, 2000; Seelos and Mair, 2005; Sobol, 2008; Sors, 2001) have used this quotation in the past twenty years, this is not satisfactory to depict the whole concept (Custance and Hillier, 1998): SD gathers together a wide array of issues such as poverty, population, social class, employment, pollution, transportation, technological innovations, trade and politics (Chaharbaghi and Willis, 1999). To review the main SD issues, Jacobs (Jacobs, 1995) has designed a model of five main attributes: efficiency, social equity, environmental integrity, quality of life and participation.

People play a crucial role in enforcing SD principles: individuals' choices have a straight influence on the evolution of societies (Pahl-Wostl, 2002). Among other behaviours to target 
SD goals, individuals can consume goods and services issued by environmentally friendly or fair-trade organisations: this will influence production in several industries (De Pelsmacker and Janssens, 2006). Also, individuals can pay attention not to waste water, electricity or gasoline (e.g. by walking or using public transport means) and can contribute to the increase of recycling rates. Therefore, individuals' attitudes and routines are relevant to SD.

To sensibilize the local community towards the main issues regarding sustainable development, the Geneva Cantonal Office of Sustainable Development (SCDD) regularly organizes public events, offers scholarships and prices, and undertakes other pedagogical actions. Among them, the "Sustainable development day" and the "Sustainable Development Brochure" are two pedagogical tools analysed in depth in this paper.

The "Sustainable development day" is an annual event held in Geneva and organised by SCDD. Born in 2002, to celebrate the $10^{\text {th }}$ birthday of the United Nations Conference on Environment and Development (UNCED) held in Rio de Janeiro in 1992, it now takes place every year in June. It aims to explain the people the main elements regarding SD issues and to present ongoing projects and actions in this field. So far, the event has always been successful in terms of participation: visitors participated to the event in 2002 were 5'000 and have constantly risen up to 20'000 in 2007 (source: http://etat.geneve.ch/dt/developpementdurable/accueil.html).

The second SD pedagogical tool under study in this paper is the "Sustainable Development Brochure" entitled "To consume responsively" published in 2005. The leaflet has been designed to offer the citizens an informational document and a decisional tool to contribute to SD in their daily routines. The brochure targets people willing to contribute to meet SD objectives who are still inactive. Among the 28'000 published booklets, about 23'000 have been distributed between 2005 and 2007. People can get the leaflet for free upon application.

In this paper, we present the main findings of a survey that attempts to measure the impact of the two SD pedagogical tools, i.e. "SD Day" and "SD Brochure" on Canton Geneva population. Thus, we would like to identify the perception and efficacy of these tools among the population under study. Thereafter, we would like to draw recommendations for policy makers active in this field within the local or in other areas.

Results and theses of this study have been presented to the Head of the Geneva Cantonal Office on Sustainable Development (SCDD) to improve both instruments and to implement design SD actions.

\section{Literature Review}

Devising public and private policies to make SD principles effective is a very challenging activity. In fact, it requires the design of actions that simultaneously allow social advancement, economic development, environmental defence and a wise use of natural resources (Custance and Hillier, 1998). Indeed, SD needs social, economic and environmental necessities to be efficiently balanced (Sors, 2001).

To achieve these goals, science works on SD compatible cutting-edge technologies that have the lowest impact on the environment. In the coming future, we can foresee the spread of nine new technologies: advanced sensors, new biotechnology techniques, clean car technologies, more efficient product recycling, new water and waste treatments, improved micro manufacturing, renewable and photovoltaic energy sources able to satisfy the demand (Dearing, 1999).

Business and industry should take part into this process: they engender economic progress and are a source of innovation (Dearing, 1999). Again, defining sustainable business is 
difficult (Wade, 1999); nevertheless, we deal with entrepreneurs that attempt to create social value through innovative business models (Seelos and Mair, 2004). Several case studies and analyses (Seelos and Mair, 2005) evidence the impact and the contribution of sustainable entrepreneurship to meet the "Millennium Goals".

Implementing SD friendly policies and technological innovations leads compliers to double-side benefits. In fact, it has been proved that that fighting against climate change provides the populations with both environmental and economic advantages (Chaharbaghi and Willis, 1999).

An empirical research conducted in Queensland (Australia) among 166 SMEs owners and managers has highlighted that in general, managers/owners think that adopting some environmental-friendly conducts has positive outcomes on their business. However, only few companies have put in practise environmentally friendly actions (Gadenne et al., 2009).

The case of Siemens (Zhao, 2004) shows a path on how organisations could practise SD principles. The German attempts to meet its requirements through encouraging SDcompatible attitudes and behaviours at all hierarchical levels. Internal controls and incentives, communication and resources optimisation are the keywords of their approach.

From a more social point of view, SD principles are still hard to enforce since its principles seem to be too far from individuals' routines (Kühtz, 2007). It is then crucial that people make efforts to make SD happen (Dearing, 1999).

To achieve this task, collective learning on SD values needs to be developed. The deployment of participatory processes that actually influence political and economic devices seem to be the highway to improve the current situation (Pahl-Wostl, 2002). Indeed, effective participatory processes should encounter knowledge sharing, congruence, resources and trust (De Marchi and Ravetz, 2001).

An empirical research conducted in Italy (Kühtz, 2007) points out that everybody is supposed to play a strategic role in meeting SD objectives. The selected sample of public and private managers, environmental advisers and the local community members underline the crucial role played by education and culture. Therefore, the author (Kühtz, 2007) recommends the implementation of continuous educational instruments additional to the traditional school system to make people aware of SD needs. Thus, individuals would accrue consciousness and be likely to change their willingness to contribute to SD.

Education relevancy in pursuing SD objectives has also been highlighted by Chaharbaghi and Willis (Chaharbaghi and Willis, 1999). According to them, interaction and experience sharing between environmentalists, economists, media, industrialists, technologists and political leaders are necessary when devising SD policies.

Teaching young generations represents a successful investment: combining effective teaching and learning strategies over these themes leads most of the students to be committed to play in favour of SD. This is one of the main findings of a research conducted in a hospitality management school (Wade, 1999). It is envisioned by the author that most of the future hospitality managers issued by that school will be effective change agents pursuing sustainable corporate policies.

Moreover, consumers' education and information are relevant to sustain fair trade purchases. An empirical study conducted on 615 Belgians evidenced that sustainable product manufacture is a more important driver than price to influence individuals' purchasing behaviours. Thus, communication on fair trade products should be well designed in order to efficiently meet the target groups to whom products are offered (De Palsmacker and Janssens, 2006).

The Hong Kong Declaration may be seen as a model of SD enforcement (Lai et al., 2006). Its objective is to foster partnership among actors through a participatory approach. In this scheme, SD criteria are compatible with market economics as they are rather based on private 
agreements among players. Dialogue and partnerships between local communities and government are of strategic importance to meet SD goals (Sobol, 2008).

Finally, Sors (Sors, 2001) highlights the worth of measuring SD in terms of decisionmaking, communication and participation. The author (Sors, 2001) analyses some of the existing SD approaches and indicators to develop a proposal for a suitable methodology to study Venice SD actions.

This literature review, far from being exhaustive, evidences that making efforts in information and education are relevant to spread individuals' consciousness towards SD principles. Also, it seems that information and education makes individuals more likely to change individuals' attitudes and behaviours and make them compliant to the main SD principles.

However, at present time too little knowledge is available to understand the design and implementation of SD pegagogical tools, notoriously the "SD Day" and "SD Brochure" under study in this paper.

Thus, we intend to discover some social patterns associated with them in a wealthy and international city, Geneva, where development drawbacks could seem far away from individuals' lives.

\section{Methodology}

This empirical study attempts to investigate the impact of two SD informational tools, i.e. "SD Day" and "SD Brochure" on the population living in Geneva and in its surrounding area (Canton).

To discover the main patterns associated with this theme, we have designed a survey administered to a sample representative of adult population (i.e. individuals aged 18 years old and more) living in the Canton. This research has encompassed the following steps: qualitative exploratory phase, surveys design, data collection and analysis.

The first phase of our research attempted to identify the underlying themes to be developed. In this exploratory phase, we conducted in-depth interviews to explore the overall perception among adults concerning this topic. Around 40 volunteers have accepted to talk freely to our interviewers about SD issues. Three main issues emerged from this qualitative stage: first of all, interviewees provided dissimilar definitions of SD and were not always willing to contribute to it. Also, not all individuals were aware of "SD Day" and "SD Brochure" actions.

On the basis of these underlying subjects subjects, that is to say, SD definition, the willingness to contribute to it and the knowledge of the two pedagogical instruments, we have designed a questionnaire administered to a random sample of Canton Geneva population.

The questionnaire (the complete questionnaire, in French, is available by the authors on request) is made up by 20 close-ended multiple-choice questions. At four questions, we asked the respondents to justify their answer (open-ended questions).

More in detail, the first part of the questionnaire (3 queries) attempted to provide an answer to the following main question: "what does sustainable development mean to the Geneva population?" This was followed by three more questions that attempted to find out whether interviewees are willing to make efforts in favour of sustainable development. In the following section, we asked three more questions to discover elements of perception concerning the two instruments (annual "SD Day" event and "SD Brochure”). Finally, we added five conclusive questions to verify the best perceived SD promotional tools and strategies. 
The respondents for this survey were selected on a random basis in the streets, open spaces and other public places in Geneva and surrounding areas to make a sample as representative as possible of the selcted population. Interviews were conducted face-to-face with our interviewers. 992 out of Canton Geneva 453’439 inhabitants (source: Geneva Cantonal Office of Statistics, OCSTAT, http://www.ge.ch/statistique) have answered to the questionnaire. Data collection was held between January and February 2008.

Our sample is made up by $49.5 \%$ of men and $50.5 \%$ women while official data (2008, source: Swiss Federal Office of Statistics, OFS) count 48\% men and 52\% women living in Canton Geneva. Nationalities of the respondents are spread as follows: 59\% are Swiss and $41 \%$ foreigners close to official data (OCSTAT) that count $62 \%$ of Swiss and $38 \%$ are foreigners.

Also, $48 \%$ of the sample works as employees, $25 \%$ are students, $11 \%$ are managers, $5 \%$ independent workers, $4 \%$ high managers, 3\% housewives/men, $3 \%$ are unemployed and $2 \%$ are retired people. The Cantonal Office of Statistics shows that 31,9\% of the Canton Geneva population is made by employees, managers are 5,3\%, independent workers are $7,6 \%$, housewives/men 4,8\%, unemployed are $4,3 \%$ and retired people are $21.7 \%$. Thus, we can affirm that in our sample students are rather over-represented and retired people are underrepresented. Finally, $71 \%$ of the respondents live in urbanised while $29 \%$ in rural areas.

Descriptive statistics of the sample as well as relationships between classes and variables have been analysed in depth. Finally, research hypotheses have been verified on the basis of statistical tests.

\section{Descriptive Statistics}

As presented in the previous section, the questionnaire we submitted to our sample is organised in three sections to attempt to discover individuals' opinion of SD, their willingness to contribute to it and the overall peception, in terms of knowledge and usefulness, of the "SD Day" annual event and the "SD Brochure" leaflet.

The first question of the first section (i.e. individuals' opinion of SD) is the following: how precise is for you the notion of "sustainable development"? 14\% of the respondents affirm to have a very precise idea of the meaning of SD, 52\% say "rather precise", 28\% "not very precise" and 6\% say "very imprecise". Cross table shows that $82 \%$ of the high managers affirm to have a "rather or very precise" idea of the meaning of SD.

Then, we have asked the respondents to quote three keywords that remind them the concept of SD. In table 1, you can find the 10 most quoted keyords to depict this concept.

Table 1: 10 main keywords associated to the "Sustainable Development" concept.

\begin{tabular}{|l|l|l|}
\hline Keywords & $\begin{array}{l}\text { No of } \\
\text { quotes }\end{array}$ \\
\hline $\begin{array}{l}\text { Energy } \\
\text { (natural/alternative/renewable/hydraulic/green/solar/eolic/electric/clean) }\end{array}$ & 371 \\
\hline & Ecology & 289 \\
\hline & Recycling / Waste collection and sorting & 272 \\
\hline & Economy / Savings & 225 \\
\hline & Environnement & 190 \\
\hline & Pollution & 87 \\
\hline
\end{tabular}




\begin{tabular}{|l|l|l|}
\hline & Nature & 79 \\
\hline & Water & 72 \\
\hline & Future (generations) & 45 \\
\hline Social & 44 \\
\hline
\end{tabular}

We asked the interviewees to rate the relevancy SD has for themselves on a scale from 0 (minimum grade) to 3 (highest mark). 38\% answer "3", followed by $42 \%$ of the sample who say " 2 ", $16 \%$ that say " 1 " and $6 \%$ who say " 1 ". It seems that women are more concerned by SD than men. Cross-tables show that $52.6 \%$ of respondents who chose the highest mark (i.e. "3") women. Simulteneously, among those who attribute the lowest grade (i.e. "0"), 57.1\% are men.

We now present results of the second section of our questionnaire. Here, we attempted to identify individuals' willingness to contribute to SD.

First of all, respondents were asked to answer to the following question "In general, do you feel encouraged to contribute to SD?" Those who agree (answer "yes") were 60\% of the sample. Negative are representative of $25 \%$ of the sample, while $15 \%$ don't know. Among "yes answerers", women might feel more encouraged to contribute to SD than men. They are respectively $52.3 \%$ against $47.7 \%$.

Also, we enquired why those who have answered "yes" to this question feel encouraged to contribute to SD and why the others ("no" answerers) are not. In brackets you will find the number of quotes.

"Yes answerers" explain their encouragement to contribute to SD by saying:

- To contribute to the survival of the planet and then for future generations. (336)

- Because there is a growing awareness and increasing actions in favour of SD. (97)

- Because of the load of information transferred via communication means. (70)

- Because solutions are being applied for recycling. (14)

- Because efforts are being made at my workplace. (6)

- Because solutions are being applied for energy saving. (5)

- Through the efforts of the public powers. (4)

- Because solutions are being applied in terms of water consumption reduction. (2)

- Because the offer of SD-compatible products is growing. (2)

- Because interesting solutions are being applied for transportation services. (1)

"No answerers" explain their lack of encouragement to contribute to SD by saying:

- We are not well informed; there are no advertisements or sensitizing campaigns running. (42)

- Because I don't feel concerned, it is not very important; it is only a fashion effect. (42)

- Because the concept of SD lacks of a precise definition, that is too abstracted. (27)

- Because there are no concrete and accesible proposals to act. (27)

- Because of a lack of constraining or encouraging measures enforced by public powers. (20)

- Because actions or activities designed in favour of SD are ridicoulous. (18)

- Because there are no economic advantages. SD is costly and is in conflit with organisations' call for profits. (11)

- Because the main economic and institutional actors don't give examples. (4)

- Because there are only few products representatives of SD. (4) 
In the following question, we asked our sample what do they actually do in their routines to contribute to SD. Interviewees had several answer possibilities available. Recycling heads with $25 \%$ of choices, followed by energy saving (21\%), water saving (19\%), ecologic transportation (14\%), fair-trade (12\%), alternative energies (6\%), I don't know (1\%), other (1\%) and nothing (1\%).

We also asked our sample "To contribute to SD, in which fields would you be willing to make extra efforts?" $27 \%$ of our sample answered "energy consumption" followed by "food purchases” (18\%), "water consumption” (17\%), “transportation” (14\%), “international help” (10\%), “clothes” (6\%), “travels \& leisures” (4\%), “I don’t know” (3\%) and "I don’t feel concerned/interested” (1\%).

We now analyse the answers provided to the third section of our questionnaire in which we made more precise questions concerning the "SD Day"and the "SD Brochure".

We first asked how people imagine a day / fair dedicated to SD. Respondents say “instructive” (32\%), "responsabiliser” (28\%), “fun” (18\%), “cultural » (12\%), "scientific” (6\%), "I don't know" (3\%) and "other" (1\%).

Afterwards, we asked the interviewees whether they were aware of the existence of the annual "SD Day" held in Geneva. Most people (76\%) don't know about it, while 24\% does.

Among the latter, $8 \%$ of them (i.e. 72) have already participated to it. They affirm the annual "SD Day" event is "informative" (32\%), "convivial” (22\%), "pedagogical” (21\%), "responsabiliser” (15\%), “enjoyable” (7\%) and "other” (3\%).

Also, among the 72 who have already participated to the event, $76 \%$ affirm to have learnt something by it, $24 \%$ have not. After their participation to the event, their daily attitudes and behaviours have proceeded as follows:

- I do nothing. (17)

- I increase waste recycling on all its forms. (12)

- I attempt to save energy. (9)

- I am more aware of the subject. (7)

- I am more attentive to water consumption. (6)

- I use more and more public transportation and other more ecological transportation means. (4)

- I would like to buy more fair trade products. (2)

- I have enrolled in an association. (1)

- I teach my children a more responsible behaviour. (1)

As for the "SD Brochure", we asked "a leaflet which encourages consuming responsively should be:" "practical" according to $30 \%$ of the sample. Then follow "visually enjoyable" (19\%), "well structured” (19\%), enjoyable (15\%), "provoking” (11\%), “theorical” (4\%) and "I don’t know" (2\%).

Then, we asked the sample whether they have already heard about the "SD Brochure". $87 \%$ have not while $13 \%$ (i.e. 126) have. Among the latter, 49 people (39\%) have had a look to it. We asked these who have already had a look to it, $46 \%$ affirm it has had a slight influence on their consumption habit, $27 \%$ say it had a strong impact, $20 \%$ say it hasn't and 7\% “I don't know".

Among those who affirm to have changed their consumption habits, they explain it by:

- I am more attentive to energy saving, e.g. purchase of low energy light bulbs, I switch off electricronic devices to avoid stand by, I use recharchable batteries. (5)

- I am more attentive to food purchases. (4)

- I am more attentive not to waste water. (2) 
- I buy environmental friendly polishing products. (2)

- I am more attentive when purchasing clothes and shoes. (2)

- I am more attentive to cosmetics. (2)

- In general, I have changed my behaviour. (2)

- I use less petrol. (1)

- I am more attentive and buy fair-trade products. (1)

We then asked respondents' who had a look to the "SD Brochure" (49), their opinion about it. People answer it is "well-structured" (33\%), "visually enjoyable” (26\%), "practical” (18\%), "enjoyable" (15\%) and “other" (8\%).

Reading this booklet is "easy" according to $95 \%$ of the respondents and difficult (5\%). Also, it is "attractive" (67\%) and "boring" (33\%).

$34 \%$ of these (49) affirm the "SD Brochure" is a useful tool (informational tool) to decide actions in favour of SD. 66\% disagree. This tool has allowed to $79 \%$ of them to have a more precise idea of the meaning of SD, it has not to 21\%. 21 out of 41 respondents think the booklet is complete, 12 do not.

We asked the whole sample "do you think a booklet on consuming responsively would help you to change your behaviour?” 53\% agree with this statement, 11\% disagree, 36\% don't know. For those who disagree, they explained their opinion by saying:

- I have already changed my behaviour in terms of responsible consumption / My behaviour is already satisfying. (25)

- Consuming responsively is too expensive for me. I cannot afford this consumption mode. (13)

- The booklet is not an adequate tool to make me change my consumption behaviour. (21)

- I don't want to change my consumption behaviour because I don't believe to responsible consumption or I don't know it. (17)

- We have finally enquired our respondents about the best way to promote SD. This question let us identify the perception of SD support actions to be undertaken.

We started by asking how public authorities should dispatch a SD booklet. Respondents say: "trough educational institutions" (25\%), "via public institutions" (20\%), at "events" (18\%), "via stands” (12\%), "trough private companies" (11\%), "other” (10\%) and "I don't know" (4\%).

Afterwards, we asked the actors supposed to be the most adequate to act in favour of SD: "State and public powers" (35\%), "educational institutions" (24\%), "private companies" (13\%), "non-governmental organisations" (13\%), “international organisations" (11\%), "I don’t know” (2\%), “other” (1\%) and “nobody” (1\%).

Therefore, we enquired how public powers should act to sensibilize Geneva population towards SD. Respondents answered as follow: "advertisement campaign" (30\%), "consumption booklet” (19\%), "sensibilising events" (16\%), "increasing regulation” (14\%), “enjoyable website” (13\%), public conferences (6\%), "I don't know” (1\%) and "other” (1\%).

We also asked whether consumers feel sufficiently informed about SD. 71\% disagree with this statement, $12 \%$ agree and $17 \%$ don't know.

We concluded our questionnaire by asking whether SD advertisement and information should rather be "incentive" (31\% of choices), pedagogical (24\%), "enjoyable” (12\%), “comparative” (12\%), “other” (1\%) and “I don’t know” (1\%). 


\section{Hypotheses testing}

Descriptive statistics have illustrated Geneva inhabitants' knowledge of SD issues, their willingness them contribute to it as well as their perception towards two SD instructional tools used by Canton Geneva (i.e. "SD Day” and "SD Brochure”).

Therefore, we can affirm that Geneva inhabitants generally feel concerned by SD issues and mostly motivated to adapt their routines to SD needs. However, individuals feel not to be sufficiently informed about SD. Also, it seems that "SD Day" and "SD Brochure" have somehow influenced the participants' and readers' behaviours. Then, public and educational institutions are mainly supposed to operate in favour of SD; promotion should carry provocative, pedagogical and enjoyable messages.

Thus, we have analysed more in depth the existing relationships among of the variables (questions) presented above. This might provide useful elements of perception to improve or re-design the two policy tools under study in this paper. Therefore, we would like to draw recommendation relevant to design effective and well-perceived SD policies on the basis of our literature review, research results and validated hypotheses.

As to hypotheses, we have made four statistical tests to verify the existance of relationships between individuals' SD knowledge, individuals' participation to the "SD Day" and individuals' reading of the "SD Brochure".

To make these tests, we have coded all questionnaires in a database through SPSS statistical software. Tests have been made according to the schemes illustrated by Bryman and Cramer (Bryman and Cramer, 2006).

The first test we are going to present aims to identify the existance of relationships between individuals' knowledge of SD and one's participation to the "SD Day", the annual event designed to inform Canton Geneva population about the main SD issues. So, we have selected two of the questions, the first one is the following: "how precise is for you the notion of 'sustainable development'?" Possible answers interviewees could choose among are defined over a qualitative scale that is "very precise", "rather precise", "rather imprecise", "very imprecise". The second question let us know individuals" participation to the "SD Day".

Possible answers respondents could make were "yes" and "no".

Thus, we are able to test a hypothesis according to the following scheme:

Ho: There is no relationship between individuals' participation to the "Sustainable Development Day” and individuals’ precise idea of Sustainable Development.

Ha: There is a relationship between individuals' participation to the "Sustainable development day” and individuals’ precise idea of Sustainable Development.

To test this hypothesis, we have used a non-parametrical test called "Kruskal-Wallis $\mathrm{H}$ test" that allows verifying relationships between two or more nominal and independent variables.

Table 2: $\quad$ Ranks, Precise idea of SD and SD Day participation

\begin{tabular}{|ll|l|l|}
\hline & $\begin{array}{l}\text { How precise is for } \\
\text { you the notion of } \\
\text { "SD”? }\end{array}$ & N & Mean Rank \\
\hline $\begin{array}{l}\text { Have you already participated } \\
\text { to the SD Day event? }\end{array}$ & $\begin{array}{l}\text { Very precise } \\
\text { Rather precise }\end{array}$ & 137 & 440.99 \\
n & 510 & 483.37 \\
\hline
\end{tabular}




\section{Table 3: $\quad$ Test Statistics (a, b)}

\begin{tabular}{|l|l|}
\hline & $\begin{array}{l}\text { Have you } \\
\text { already } \\
\text { participated } \\
\text { to the SD } \\
\text { Day event? }\end{array}$ \\
\hline $\begin{array}{l}\text { Chi-Square } \\
\text { Df } \\
\text { Asymp.Sig. }\end{array}$ & $\begin{array}{l}40.451 \\
.000\end{array}$ \\
\hline
\end{tabular}

a. Kruskal-Wallis Test.

b. Grouping Variable: "How precise is for you the notion of SD?"

We have retained a significance level of $5 \%$ that is the first-type error (or the risk to reject the null hypothesis when it is actually correct). The p-value of 0.000 indicates that we can reject the null hypothesis at the significance level of 5\%. Thus, we can affirm that there is a relationship between individuals' participation to the "SD Day" and the preciseness of their idea of the SD concept.

We go further with our investigation by verifying whether similar attitudes can be acknowledged with the second pedagogical tool under analysis, i.e. the "SD Brochure". Thus, we have tested the existence of a relationship between having had a look to the "SD Brochure" and the preciseness of the idea of SD.

To do so, we have retained the tow following questions, the first being: "how precise is for you the notion of 'sustainable development'?” Possible answer interviewees could choose among are defined over a qualitative scale that is "very precise", "rather precise", "rather imprecise", "very imprecise". The second question let us know whether individuals have had a look at the "SD Brochure". Possible answers respondents could make were either "yes" or "no".

Thus, we are able to test a hypothesis according to the following scheme:

Ho: There is no relationship between individuals who have had a look at the "Sustainable Development Brochure” and individuals’ precise idea of Sustainable Development.

Ha: There is a relationship between individuals who have had a look at the "Sustainable Development Brochure” and individuals’ precise idea of Sustainable Development.

Again, to test this hypothesis, we have used a non-parametrical test called "Kruskal-Wallis $\mathrm{H}$ ” test. As in the previous case, we are dealing with dichotomous and rank nominal variables.

Table 4: $\quad$ Ranks, Precise idea of SD and had a look at the SD Brochure

\begin{tabular}{l|l|l|}
$\begin{array}{l}\text { How precise is for } \\
\text { you the notion of }\end{array}$ & $\mathrm{N}$ & Mean Rank \\
\hline
\end{tabular}




\begin{tabular}{|ll|l|l|}
\hline & "SD”? & & \\
\hline Have you already & Very precise & 139 & 467.36 \\
had a look at the & Rather precise & 509 & 482.32 \\
"SD Brochure”? & Rather imprecise & 274 & 505.88 \\
& Very imprecise & 54 & 513.00 \\
& Total & 976 & \\
\hline
\end{tabular}

\section{Table 5: $\quad$ Test Statistics (a, b)}

\begin{tabular}{|l|l|}
\hline & $\begin{array}{l}\text { Have you } \\
\text { already had } \\
\text { a look at the } \\
\text { "SD } \\
\text { Brochure”? }\end{array}$ \\
\hline $\begin{array}{l}\text { Chi-Square } \\
\text { Df } \\
\text { Asymp. Sig. }\end{array}$ & $\begin{array}{l}17.304 \\
\text {.001 }\end{array}$ \\
\hline
\end{tabular}

a. Kruskal-Wallis Test.

b. Grouping Variable: "How precise is for you the notion of SD?"

We have retained a significance level of $5 \%$ that is the first-type error (or the risk to reject the null hypothesis when it is actually correct). The p-value of 0.001 indicates that we can reject the null hypothesis at the significance level of 5\%. Thus, we can affirm that there is a relationship between individuals' had a look to the "SD Brochure" and the preciseness of their idea of SD.

Thus, we have evidenced the existence of relationships between individuals' experience of both pedagogical tools (i.e. "SD Day" and "SD Brochure") and the preciseness of the SD concept. Therefore, we can affirm that people who had experienced either of the two instruments are more likely to know the notion of SD than the others.

We have finally checked existence of a relationship between the two tools under study. Indeed, we would like to verify the connection between individuals' knowledge of the "SD Day" annual event and their knowledge of the "SD Brochure" and vice-versa.

To verify the existence of a relationship, we have retained the following question, the first one being the following: "have you already heard about the 'SD Day' annual event organised every year in June in Geneva?" Possible answers interviewees could choose among were "yes" and "no". The second question let us know whether individuals have already heard about the "SD Brochure". Here too, the possible answers respondents could give were "yes" and "no".

Thus, we are able to test a hypothesis according to the following scheme:

Ho: There is no relationship between individuals' knowledge of the "Sustainable development day" annual event and those who have heard about the"Sustainable Development Brochure”.

Ha: There is a relationship between individuals' knowledge of the "Sustainable development day" annual event and those who have heard about the"Sustainable Development Brochure”. 
Since we are dealing with two independent dichomotous variables, we use the Chi-Square statistical test to test this hypothesis.

Table 6: $\quad$ Chi-Square test. Knowledge of SD Day and SD Brochure

\begin{tabular}{|l|l|l|l|l|l|}
\hline & Value & df & $\begin{array}{l}\text { Asymp. Sig. } \\
\text { (2-sided) }\end{array}$ & $\begin{array}{l}\text { Exact Sig. } \\
\text { (2-sided) }\end{array}$ & $\begin{array}{l}\text { Exact Sig. } \\
\text { (1-sided) }\end{array}$ \\
\hline Pearson Chi-Square & $\begin{array}{l}55.023(\mathrm{~b} \\
\text { (1) }\end{array}$ & 1 & .000 & & \\
$\begin{array}{l}\text { Continuity } \\
\text { Correction (a) }\end{array}$ & 53.386 & 1 & .000 & .000 & .000 \\
$\begin{array}{l}\text { Likelihood Ratio } \\
\text { Fisher's Exact Test }\end{array}$ & 48.205 & 1 & .000 & & \\
$\begin{array}{l}\text { Linear-by-Linear } \\
\text { N of Valid Cases }\end{array}$ & 54.967 & 1 & .000 & & \\
\hline
\end{tabular}

a. Computed only for a $2 \mathrm{x} 2$ table.

b. 0 cells $(.0 \%)$ have expected count less than 5 . The minimum expected count is 30.64.

With a significance level of $95 \%$, the p-value of 0.000 allows us to reject the null hypothesis. We can then affirm that there is a relationship between people who have already heard of the "SD Day" and those who have heard about the "SD Brochure". People who acknowledge either of the tools are more likely to be aware of the other.

Finally, we would like to identify the existence of a relationship between individuals' experience of one of the two tools (i.e. "SD Day" and "SD Brochure").

To verify the existence of a relationship, we have retained these two questions: "have you already participated to the 'SD Day' annual event organised every year in June in Geneva?" Possible answers interviewees could choose among were "yes" and "no". The second question let us know whether individuals have already had a look at the "SD Brochure". Again, the possible answers respondents could give were "yes" and "no".

Thus, we are able to test a hypothesis according to the following scheme:

Ho: There is no relationship between individuals' experience of the "Sustainable Development Day" annual event and those who have had a look at the"Sustainable Development Brochure”.

Ha: There is a relationship between individuals' experience of the "Sustainable Development Day" annual event and those who have had a look at the“SD Brochure.

Since we are dealing with two independent dichomotous variables, we use the Chi-Square statistical test to test this hypothesis.

Table 7: $\quad$ Chi-Square test, Experience of SD Day and SD Brochure 


\begin{tabular}{|l|l|l|l|l|l|}
\hline & Value & Df & $\begin{array}{l}\text { Asymp. Sig. } \\
\text { (2-sided) }\end{array}$ & $\begin{array}{l}\text { Exact Sig. } \\
\text { (2-sided) }\end{array}$ & $\begin{array}{l}\text { Exact Sig. } \\
\text { (1-sided) }\end{array}$ \\
\hline Pearson Chi-Square & $\begin{array}{l}42.023(\mathrm{~b} \\
\text { (1) }\end{array}$ & 1 & .000 & & \\
$\begin{array}{l}\text { Continuity } \\
\text { Correction (a) }\end{array}$ & 38.606 & 1 & .000 & .000 & .000 \\
$\begin{array}{l}\text { Likelihood Ratio } \\
\text { Fisher's Exact Test }\end{array}$ & 26.409 & 1 & .000 & .000 & \\
$\begin{array}{l}\text { Linear-by-Linear } \\
\text { N of Valid Cases }\end{array}$ & 91.980 & 1 & .000 & & \\
\hline
\end{tabular}

a. Computed only for a $2 \times 2$ table.

b. 0 cells $(.0 \%)$ have expected count less than 5 . The minimum expected count is 3.95.

With the significance level of $5 \%$, the p-value of 0.000 allows us to reject the null hypothesis. We can then affirm that there is a relationship between people who have already experienced the "SD Day" and those who have already had a look at the "SD Brochure". People who experience either of the two tools are more likely to use the other. Therefore, experiencing one of pedagogical instrument seems not to exclude the use of the other.

\section{Conclusions}

In this paper, we attempt to explore the perception of Canton Geneva inhabitants towards the "Sustainable development day" and the "Sustainable Development Brochure". The local State authority has been implementing both pedagogical tools in the past few years to increase individuals' awareness towards Sustainable Develoment (SD) issues.

Thus, we have made an empirical study (survey) to detect some elements of perception regarding these tools among Canton Geneva population to provide policy makers active in this field with useful recommendation at both local and in other contexts.

Our literature review has acknowledged that education plays a crucial role to influence individuals' attitudes and behaviours to meet SD requirements: either or both pedagogical instruments could have a positive impact among Geneva inhabitants. Therefore, we wanted to identify whether these instruments have influenced individuals' attitudes and behaviours in their routines. Also, we expected to collect feedbacks to improve both devices in use (i.e. "SD Day" and "SD Brochure").

992 people who live and work in Canton Geneva have answered to our questionnaire between January and February 2008.

Descriptive statistics show that Geneva inhabitants generally feel concerned by SD issues and mostly motivated to adapt their daily routines to SD needs. However, individuals feel not to be sufficiently informed about SD. Also, it seems that "SD Day" and "SD Brochure" are well perceived by the population who have already experienced them. Users feel that the "SD Day" and "SD Brochure" have slightly influenced their behaviour making their routines more 
SD-friendly. Then, public and educational institutions are mostly supposed to operate in favour of SD; promotion should carry provocative, pedagogical and enjoyable messages. Therefore, we have made four non-parametrical statistical tests to indentify the existence of relationships between the variables under study. In particular, we evidenced a relationship between the participation to the "SD Day" and the preciseness of SD notion. This means that individuals who have experienced the event are more likely to have better knowledge of SD than the others. A further relationship has been verified between "SD Brochure" reading and the preciseness of SD notion. Again, users who had access to this tool are more likely to have a more precise idea of SD than the others. Thus, we can affirm that people who experienced either pedagogical tools are more likely feel more informed about SD than the others.

Although the nature of the relationship i.e. whether it is due by learning or self-selection is unclear, the implementation of a "SD Day" and a "SD Brochure" can be considered as a useful informational supports when designing public policies. Indeed, its consumers seem to be more likely to acknowledge SD relevancy than the others.

Afterwards, we have evidenced a further connection between individuals' knowledge of "SD Day" and those who have already heard about "SD Brochure". Thus, we can affirm that people awareness of either of the tools are more likely to know the other. Finally, it seems that experiencing either of the two pedagogical instruments is not mutually exclusive. On the contrary, people who have experienced "SD Day" or had a look at the "SD Brochure" are more likely to have had access to the other instrument than the others. Here we evidence the relationship between people who have access to either of the two pedagogical tool are more likely to know the other than other individuals of living in the selected area. Again, we have not sufficient data available to point out whether the relationship is due to learning or selfselection. This causality identification extends our research to be developed in other works.

This research encounters limitations due to the research design: first of all, there is a sampling bias. Although the questionnaires were accurately randomly submitted, in different parts of the city and surrounding areas during different hours and days, the sample may not be precisely representative of the Geneva population. We showed in the "methodology" section of this paper some differences existing between our sample and official data. Then, validity and reliability risks are always attached to survey research (Equey and Fragnière, 2008; Garrods and Willis, 1999).

Finally, our survey has been administered at Canton Geneva only. Although the Swiss state has a wide international population, it is still difficult to make reliable extensions to different contexts. Further studies should then replicate this research elsewhere in Europe and overseas.

\section{Acknowledgements}

An earlier version of this paper has been presented to the Climate - Klima 2009 online conference organized by Hamburg University of Applied Sciences last 2 - 6 November 2009. Therefore, we would like to thank an anonymous referee as well as the participants to this event for their valuable comments.

Also, we are also thankful to Geneva Cantonal Office on Sustainable Development (SCDD) who widely supported this research.

Finally, we are indebted to the students of LEM (Laboratoire d'Études de Marché) of Geneva Haute École de Gestion, who participated in the construction of the survey, data collection, and the transcription of answers. Without them, this research would not have been possible. 


\section{7. $\quad$ References}

Bryman, A., Cramer, D. (2006). Quantitative Data Analysis for the Social Scientist with SPSS 15 \& 16, Routledge, London, United Kingdom.

Byrch, C., Kearing, K., Milne, M., Morgan, R. (2007), “Sustainable 'what'? A cognitive approach to understanding sustainable development", Qualitative Research in Accounting \& Management, Vol. 4, No.1, pp. 26-52.

Catenazzo, G., D’Urso, J., Fragnière, E. (2008), “Elements of perception regarding Sustainable Development in Geneva”, paper presented at the Klima/Climate 2008 conference, Hamburg University of Applied Sciences, Hamburg, Germany, November 3-7, 2008.

Chaharbaghi, K., Willis, R. (1999), “The study and practice of sustainable development”, Engineering Management Journal, Vol. 9, No. 1, pp. 41-48.

Custance, J., Hillier, H. (1998), "Statistical issues in developing indicators of sustainable development”, Journal of the Royal Statistics Society Series A, Vol. 161, No. 3, pp. 281-290.

Dearing, A. (1999), "Have we the foresight for sustainable development?", The journal of future studies, strategic thinking and policy, Vol. 1, No. 2, pp. 131-142.

De Marchi, B., Ravetz, J. R. (2001), “Participatory Approaches to Environmental Policy”, working paper, Cambridge Research for the Environment (CRE), Cambridge, United Kingdom.

De Pelsmacker, P., Janssens, W. (2006), “A Model for Fair Trade Buying Behaviour: The Role of Perceived Quantity and Quality of Information and of Product-specific Attitudes”, Journal of Business Ethics, Vol. 75, pp. 361-380.

Equey, C., Fragnière, E. (2008), "Elements of Perception Regarding the Implementation of ERP Systems in Swiss SMEs”, International Journal of Enterprise Information Systems, Vol. 4, No. 3, pp. 1-8.

Gadenne, D. L., Kennedy, J., Mc Keiver, C. (2009), “An Empirical Study of Environmental Awareness and Practises in SMEs”, Journal of Business Ethics, Vol. 84, pp. 45-63.

Garrods, G., Willis, K.G. (1999), Economic Valuation of the Environment, Edward Elgar, Cheltenham, United Kingdom.

Garvare, R., Isaksson, R. (2001), "Sustainable development: extending the scope of business excellence models”, Measuring Business Excellence, Vol. 5, No. 3, pp. 11-15.

Jacobs, M. (1995), "Reflections on the Discourse and Politics of Sustainable development", working paper, Centre for the Study of Environmental Change, Lancaster University, United Kingdom. 
Kühtz, S. (2007),“Adoption of sustainable schemes and behaviours in Italy - Barriers and solutions, what can educators do?”, International Journal of Sustainability in Higher Education, Vol. 8, No. 2, pp. 155-169.

Lai, L. W. C., Chau, K. W., Ho, D. C. W., Lorne, F. T. (2006), “A 'Hong Kong' model of sustainable development”, Property Management, Vol. 24, No. 3, pp. 251-271.

Pahl-Wostl, P. (2002), “Towards sustainability in the water sector - The importance of human actors and processes of social learning”, Aquatic Sciences, Vol. 64, pp. 394-411.

Rondinelli, D. A, Berry, M. A. (2000), "Environmental Citizenship in Multinational Corporations: Social Responsibility and Sustainable Development”, European Management Journal, Vol. 18, No. 1, pp. 70-84.

Seelos, C., Mair, J. (2004), "Social Entrepreneurship - The Contribution of Individual Entrepreneurs to Sustainable Development”, Working Paper No. 553, IESE Business School, Barcelona, Spain.

Seelos, C., Mair, J. (2005), "Sustainable development: how social entrepreneurs make it happen”, Working Paper No. 611, IESE Business School, Barcelon, Spain.

Sobol, A. (2008), "Governance barriers to local sustainable development in Poland", Management of Environmental Quality: An International Journal, Vol. 19, No. 2, pp. 194203.

Sors, J.C. (2001), "Measuring Progress towards Sustainable Development in Venice: A Comparative Assessment of Methods and Approaches", Working Paper No. 16.2001, Fondazione Enrico Mattei, Italy.

Wade, J. A. (1999), "Students as environmental change agents", International Journal of Contemporary Hospitality Management, Vol. 11, No. 5, pp. 251-255.

Zhao, F. (2004). "Siemens' business excellence model and sustainable development", Measuring business excellence, Vol. 8, No. 2, pp. 55-64. 